\title{
Preparing Child Psychologists for Managed Care: Educational and Training Considerations
}

\author{
Daniel B. Pickar, PhD \\ Rhonda L. Lindsey, PsyD
}

\begin{abstract}
In today's health care marketplace dominated by Health Maintenance Organizations and managed care, psychology internship and residency programs must increasingly prepare child psychologists to practice in a variety of managed care settings. Educational and training considerations are outlined to provide a framework for supervising child psychologists in such settings. Principles of practice in managed care are first addressed. Training should be guided by both the teaching of evidence-based practices and common factors research emphasizing the nontechnical aspects of care (i.e., therapeutic alliance, client/extratherapeutic factors). The utility of integrative child and family therapy models is highlighted, and training recommendations specific to managed care settings are presented. [Brief Treatment and Crisis Intervention 8:370-380 (2009)]
\end{abstract}

KEY WORDS: managed care, child psychology training, clinical supervision, brief psychotherapy, child and adolescent psychotherapy.

The most profound development that has impacted the training and employment of psychologists over the last 30 years has been the advent of managed care organizations. The Health Maintenance Organization (HMO) Act of 1973 emerged as a response to the spiraling cost of health care. Although many psychologists continue to decry the evils of managed care, others accept the viewpoint espoused by Cummings, Budman, and Thomas (1998) that "managed care rescued our health system from a potentially lethal, out of control inflationary

From the Department of Child and Family Psychiatry, Kaiser Permanente Medical Center, Santa Rosa.

Contact author: Daniel B. Pickar, Staff Psychologist Department of Child and Family Psychiatry, Kaiser Permanente Medical Center, 401 Bicentennial Way, Santa Rosa, CA 95403. E-mail: dan.pickar@kp.org.

doi:10.1093/brief-treatment/mhn024

Advance Access publication on January 6, 2009 spiral" (p. 460). Regardless of one's point of view, managed behavioral health care is here to stay, and the majority of mental health patients receive treatment under some type of a managed care plan.

Psychologists must be prepared to work in institutional HMO settings (i.e., such as a staffmodel HMO, which employs a salaried medi$\mathrm{cal} /$ mental health staff). Additionally, because the vast majority of reimbursement for private outpatient mental health services is administered by managed care organizations (i.e., such as group-model HMOs, network-model HMOs, or independent practice associations [IPAs]), psychologists in private practice must also be prepared to interface with managed care.

Concurrent with changes in the health care environment over the last quarter of a century, psychologists have increasingly been trained

(c) The Author 2009. Published by Oxford University Press. All rights reserved. For permissions, please e-mail: journals.permissions@oxfordjournals.org. 
and employed in managed care settings. For example, Kaiser Permanente Medical Centers in Northern California is a staff-model HMO that employs almost 400 psychologists, and over 100 psychology interns or postdoctoral residents are trained each year. In order to produce psychologists who are capable of meeting current market demands, previous authors have not only advocated in favor of including coursework on managed care in graduate school programs in professional psychology (Daniel, Alva, \& Olivares, 2002) but have also emphasized the need for internship and postdoctoral training programs to prepare psychologists to work in managed care settings (Spruill \& Pruitt, 2000).

The last two decades has also seen an abundance of books and scientific articles on various models of short-term psychotherapy for adults in managed care settings (Austad \& Berman, 1991; Budman \& Gurman, 1988; Chambliss, 2000; Hoyt, 1995), a phenomenon also shaped by managed care's emphasis on cost-effective treatment. Conversely, there has been drastically less written on the provision of mental health services to children and families in managed care settings, with only one book written specifically on this topic almost 20 years ago (Kreilkamp, 1989). Similarly, the vast majority of journal articles addressing educational and training issues for psychologists in HMO settings are focused on adult treatment, with little to nothing written specifically about training child psychologists to work in managed care settings.

This article addresses this gap in the literature by focusing on critical educational and training considerations for preparing child psychologists to work in managed care settings. However, the principles of treatment and training offered here apply to the work of child psychologists in many other mental health settings, where time-efficient and cost-effective treatment must be practiced so rapid, and accessible care can be provided to children and families in need of service.

Principles of mental health practice in managed care environments will first be addressed, followed by a discussion of the importance of utilizing information from psychotherapy research to guide training and supervision. The learning of evidence-based practices (EBPs) is emphasized (Kazdin \& Weisz, 2003), but training child psychologists to recognize and incorporate the "common factors" (Hubble, Duncan, \& Miller, 1999; Lambert \& Ogles, 2004) that impact psychotherapeutic effectiveness is also underscored. The utility of integrative child and family therapy models will be highlighted, as well as training recommendations specific to the managed care setting.

\section{Principles of Practice in Managed Care}

Managed care has always been associated with short-term psychotherapy, but brief therapy predated the advent of managed care. Garfield's (1978) review of data on the length of psychotherapy in a variety of settings from 1948 to 1970 revealed that the median number of sessions in most settings was between five and six. The robustness of this finding is evidenced by the fact that more recent research has also shown that the typical duration of psychotherapy is approximately five sessions, irrespective of setting (Hansen, Lambert, \& Forman, 2002). These typical treatment durations are also consistent with research on patient expectations regarding the length of therapy, indicating that most patients prefer to be helped as quickly as possible. The myth of the superior effectiveness of long-term over short-term therapy pervaded the field for many years, but metaanalytic dose-effects research has consistently shown that by the eighth session of therapy, $50 \%$ of clients show clinically significant improvement (Hansen et al., 2002). Although 
a greater number of patients report improvement with additional therapy, the metaanalytic study by Orlinsky and Howard (1986) concluded that the major positive impact of therapy occurred in the first six sessions, followed by continuing but decreasing positive impact for approximately the next 10 sessions.

A key characteristic of staff- and groupmodel HMOs is that the responsibility of the mental health staff is to be readily available to provide therapy to the entire population served by the HMO, not just those patients in the therapist's office. For child psychologists, one of the first lessons is that managed care is not just about the provision of brief therapy but, rather, about the cultivation of a particular mind-set or attitude by the therapist that can positively or negatively interface with the patients' attitudes about brief therapy or managed care (Jung, Pomerantz, Tuholski, \& Sullivan, 2001). Below are five guiding mindsets or principles for child psychologists who receive training in managed care settings.

1. Utilize a family practice or developmental model. Many problems arise as children and families move through the life cycle and accommodate to either changing developmental stages (i.e., beginning preschool, kindergarten, junior high or high school, puberty) or to crises within the family (i.e., divorce, relocation, death of a grandparent, illness of a child, traumatic accident). Frequently, the therapist assists by normalizing and reframing issues that place the problem in a developmental framework. Just as the family practitioner is available to children and families on an ongoing basis to deal with medical issues as they arise, the child psychologist working from a family practice perspective has a long-term relationship with a family characterized by "intermittent therapy throughout the life cycle" (Cummings, 1990; Peake, Borduin, \& Archer, 2000). This is quite different from a pathology or "cure" orientation, as potential problems arising in the life of a child are viewed as an inevitable and normal part of development.

2. Maintain a "health" versus an "illness" orientation. While maintaining an appreciation for the role of psychiatric diagnosis, a health, as opposed to an illness orientation helps the child or family build on their existing strengths, skills, and capacities (Budman \& Gurman, 1988). It is important to help the family to understand the positive aspects of their child's personality and areas of mastery, as well as to encourage the family to use social supports and naturally occurring "environmental therapies" (i.e., sports, development of special talents to enhance self-esteem, activity groups to assist with social skills) to aid in improving the problem area.

3. Use of the "least radical intervention." The solution-focused therapists (deShazer, 1985) emphasize using simple interventions based on simple assumptions first, before proceeding to more complex lengthy interventions with children or families. This is consistent with the principle of parsimony. For example, a 4-year-old girl's separation anxiety involving not wanting to sleep in her own bed might first be handled with a positive reinforcement plan and graduated exposure training taught to the parents, prior to embarking on more extensive family or individual therapy. Child psychologists should also be taught to appreciate and recognize that healthy change in one area of functioning may have positive "ripple effects" into other areas. 
4. Be multitheoretical and technically eclectic. Some therapists define themselves as working from a particular theoretical orientation, whereas others view themselves as eclectic or integrative in approach. Regardless of orientation, therapists working in a managed care setting must be flexible and "do what works." Thus, even if one is theoretically orthodox, it is important to be technically eclectic. In managed care settings, it is best to be multitheoretical, in order to apply the most effective therapy for the particular problem, as opposed to trying to fit the patient into the mold of the therapist's preferred school of therapy.

5. Remain mindful of the essential characteristics of brief therapy in managed care. Several authors (Austad \& Berman, 1991; Budman \& Gurman, 1998; Hoyt, 1995, 2000) have similarly described key characteristics of brief therapy in managed care settings, which include (a) rapid assessment, diagnosis and initiation of treatment; (b) the maintenance of a clear and specific focus resulting from identifying with the patient's achievable, measurable goals; (c) a high level of therapist activity; (d) flexible use of interventions and time; (e) use of multiple formats and modalities, such as individual and group therapy, family therapy, parent consultation, psychoeducational groups and psychiatric medications; (f) utilization review and outcome measurement to insure services are being delivered in the most effective and cost-efficient manner.

\section{Utilizing Psychotherapy Research to Guide Training and Supervision}

Child psychologists in training should become familiar with the two most important areas in psychotherapy research today: (a) the empirically supported treatment (EST) movement, which posits that specific ingredients or techniques are responsible for therapeutic success (i.e., treatment or therapy manuals derive from this approach) and (b) the common factors approach, which proposes that there is a common set of factors across all schools of therapy, that primarily accounts for the efficacy of psychotherapy. Because there has been considerable debate in the literature regarding these two approaches (Chwalisz, 2001; Wampold, 2001), the American Psychological Association (APA) recently convened a presidential task force on EBPs (APA Presidential Task Force on Evidence-Based Practice, 2006), which stressed the validity of both approaches. The APA task force agreed upon an expanded definition of EBP, stating, "Evidence-based practice in psychology (EBPP) is the integration of the best available research with clinical expertise in the context of patient characteristics, culture, and preferences" (p. 5). Furthermore, the report not only emphasized the importance of specific treatment methods but highlighted the vital contribution of the individual psychologist, the treatment relationship and patient factors to the success of therapy. Other major national task forces, such as the President's New Freedom Commission on Mental Health (2003) and the Annapolis Coalition on Behavioral Health Care (2007), have also recommended that mental health training emphasize both EBPs with culturally competent care and the development of strong therapeutic alliances.

Most managed behavioral health care organizations have implemented EBPs through the development of clinical best practice guidelines, stemming from managed care's emphasis on maximizing treatment effectiveness while providing cost reductions. Child psychologists trained in managed care settings will have the benefit of exposure to a range of EBPs, many of which have been modified for application to the 
real-world clinical setting, as opposed to the research or university environment. For example, the majority of Child and Family Psychiatry Departments in the 19 Northern California Kaiser Medical Centers offer a broad range of individual and family-based EBPs, such as cognitive-behavioral therapy (CBT) for childhood depression and anxiety (Freidberg \& McClure, 2002; Ollendick \& King, 1998), brief strategic family therapy for oppositionaldefiant and conduct disorders (Szapocznik \& Williams, 2000), behavioral family systems therapy for teens with anorexia nervosa and bulimia (Robin, 2003), and dialectical behavior therapy for suicidal teenagers (Miller, Rathus, \& Linehan, 2007). Additionally, psychology interns and residents within the Kaiser system are frequently trained in a number of groupbased EBPs, including CBT depression groups for adolescents (Kazdin \& Weisz, 2003), CBTbased anxiety or obsessive-compulsive disorder groups for children (March \& Mulle, 1998; Ollendik \& King, 1998) and parent management training for conduct-disordered teenagers (Fry, Johnson, Melendez, \& Morgan, 2002; Kazdin, 1997). Also offered are preschool intervention programs based upon parent-child interaction therapy (Hembree-Kigin \& McNeil, 1995), as well as attention-deficit/hyperactivity disorder parent training programs (Barkley, 1997). Thus, in many managed care settings, child psychology trainees have the opportunity to fill their "therapeutic toolbox" with a number of these EBPs, so they can then apply and practice these treatments in a variety of settings.

The common factors research is at variance with the EST movement's emphasis on circumscribed therapeutic techniques for specific psychiatric disorders. For example, meta-analytic studies conducted over the last 30 years have shown that one model of treatment is not superior to the other but, rather, have revealed no differences in effectiveness among the various psychotherapies (Hubble, Duncan, \& Miller,
1999). In reviewing the psychotherapy outcome literature, Lambert and Ogles (2004) concluded that four factors accounted for improvement in all psychotherapy treatment: (a) $30 \%$ was found to be attributable to the therapy relationship (i.e., therapeutic alliance, caring, empathy, warmth), (b) $40 \%$ was attributable to client/extratherapeutic factors (i.e., client strengths, supportive elements in the environment), (c) 15\% was due to expectancy effects (i.e., hope, placebo, client belief in the treatment rationale, and (d) only $15 \%$ was attributable to specific models or techniques. Therefore, many prominent psychotherapy researchers (Lambert \& Ogles, 2004; Wampold, 2001; Westen, Novotny, \& Thompson-Brenner, 2004) have argued that the current emphasis on ESTs is misguided, as research supporting one form of therapy as superior to another is lacking.

Although the vast majority of meta-analytic research examining ESTs and common factors is based upon studies of adult psychotherapy, the conclusions from the few meta-analytic studies of treatment effectiveness in child psychotherapy are equally polarized. Weisz, Jensen-Doss, and Hawley (2006) concluded from their meta-analysis of child and family psychotherapy research that ESTs have generally outperformed "usual care" in direct, randomized comparisons, although effects at posttreatment were in the small to medium range. However, two other meta-analytic studies (Miller, Wampold, \& Varhely, 2008; Spielmans, Pasek, \& McFall, 2007) found that only a very small portion of the variance in youth treatment was attributable to specific factors. The findings and conclusions from these later studies are consistent with the common factors approach, emphasizing that nontechnical aspects of psychotherapy are most responsible for treatment effectiveness.

What are the implications of this controversy for educating and training child psychologists? Psychology residents and interns should 
certainly be trained in EST's, as the learning of specific techniques and models is a crucial component of the foundation upon which psychologists learn their trade. However, the common factors research findings are inconsistent with an excessive reliance on the narrow application of empirically validated methods. The importance of relationship factors to outcome in treatment, irrespective of therapy model, means that child psychologists must learn to develop relationships with children and their parents characterized by warmth, acceptance, and kindness. Several studies (Creed \& Kendall, 2005; Shirk \& Karver, 2003) found that the quality of the therapeutic relationship was related to outcome across diverse types and modes of child treatment. The therapeutic alliance in child and family work is more complex than in adult therapy, as it involves the therapist's relationship not only with the child but also with the parents. For example, a strong parent-therapist alliance has been found to be significantly related to several measures of therapy retention, including level of family participation, frequency of cancellations and no-shows, and therapist concurrence with termination (Hawley \& Weisz, 2005).

Lastly, given the common factors research showing that treatment outcome is also largely determined by client/extratherapeutic factors, psychologists need to assist families in increasing environmental supports, while decreasing environmental detriments that impact child or family functioning. Therefore, in training child psychologists, it should be underscored that although ESTs provide specific techniques and models, the common factors provide a broad, guiding structure for the therapy.

\section{The Value of Integrative Models}

In managed care settings where brief, timeefficient therapy is the norm, child psychologists need to be taught to provide psychotherapeutic interventions closely tailored to the specific needs of the child and family. One of the main criticisms of most ESTs is the assumption that most patients either have or can be treated as if they have one primary syndrome for which a single treatment can be employed (Westen \& Bradley, 2005). In the real world of clinical practice with children and families, a single syndrome or problem is more the exception than the rule. In most instances, clinical work with children and families needs to be integrative in nature. Child therapy, by necessity, typically requires the involvement of other family members, as well as the utilization of varied interventions stemming from systemic, behavioral, dynamic, or cognitive approaches. Multimodal approaches may be necessary, so the family system can support and maintain the behavioral changes in a child. Additionally, Cook and Tedeschi (2007) noted that integrative approaches with children and families are especially important to meet the diverse needs of varied ethnic and cultural groups.

Wachtel (1994) has developed a highly useful integrative model applicable to the real-world clinic setting of children and families who present with comorbid and complex clinical problems requiring intervention on several fronts. Wachtel's "child-in-family-therapy" integrates structural family therapy, behavioral, and psychodynamic approaches. Multiple treatment modalities may be used either concurrently or in sequential order, which may include family therapy, psychodynamic play therapy, and parent consultation, incorporating both developmental education and behavior therapy. Wachtel postulates that both the individual and systemic meaning of a youngster's symptoms must be addressed, and that no one perspective sufficiently addresses the multiplicity of factors that result in emotional distress. Active interventions are utilized to both alter the family system and influence the child's dynamic 
conflicts. This model provides a guiding structure and set of principles, but the treatment plan is individually crafted to meet the particular needs of the child and family.

Interventions are relatively short term in nature in this integrative model, which is highly applicable to managed care settings, and is especially suitable for ethnically and culturally diverse populations served in many mental health clinics, whereby family therapy is a crucial compliment to individual work with a child.

\section{Training Recommendations with Interns and Residents in Managed Care}

In managed care settings, there are several unique supervision issues involved in the training of child psychologists. Some residents and interns arrive at managed care settings with little formal training in brief therapy. There are some specific technical challenges for child psychologists in conducting brief therapy with children. First, the inexperienced brief therapist may waver between two extremes: difficulty sticking to the focal issues or goals of the therapy or overly pressuring the child to give up whatever he or she is doing in order to talk specifically about the treatment goals. Supervisees should be assisted to follow the child's lead, weaving in the focus, rather than intruding or coercing them to talk about specific issues. Although brief child play therapy or other types of therapeutic interventions with children can be directive, the child psychologist should also be helped to understand the connection of symbolic, child-initiated play activities, to the focal issues at hand. Second, therapists learning to conduct short-term therapy with children may display resistance to bringing-up or working on termination issues. Because separation and loss are painful, there may be a tendency by the child psychologist in training to underestimate, avoid, or postpone the fact of the approaching termination, therefore providing little help to the child in facing the potential discomforts of saying goodbye.

In today's health care environment, trainees must learn to conduct a number of evidencebased treatments, as the trend is that health insurers may only reimburse such empirically validated treatments in the future. This can happen in three ways. First, trainees need to have opportunities to colead group-based EBTs with an experienced clinician. Second, optimal training requires that trainees have a variety of supervisors with differing areas of expertise, which provides another means of exposure to different EBTs practiced by the supervisors. Third, exposure to EBTs should also take place in seminars offered by the mental health department where training is occurring. Although there is a value to EBTs being learned in their pure forms, supervisors should also emphasize flexibility in conducting evidencebased treatments. For example, Kendall and Beidas (2007) cautioned against rigid fidelity to manualized treatment of children and families, instead stressing "flexibility within fidelity" (p. 16), so that treatments can be tailored for children based upon their developmental level and unique needs.

Although brief therapy is effective with most child and family issues, supervisors must assist trainees in discerning clinical problems requiring longer term therapy, such as a child who may have been exposed to abuse or trauma or severely depressed or neglected children for whom basic trust is absent.

Psychology residents and interns also need assistance in decision making regarding the most appropriate and time-efficient form of treatment for a particular clinical problem. Psychologists working in a staff- or group-model HMO are provided with a constant flow of new patients. The pace is rapid, and demands for service are consistently high. Spruill and 
Pruitt (2000) noted that in managed care, trainees have to develop the skills for using their time efficiently and become adept at juggling current caseloads while taking on new clients. Residents and interns must also be taught how to make decisions about the frequency and intensity of treatment, when to begin seeing a client for less frequent sessions, and when to end a course of treatment.

The common factors research previously discussed highlighted the crucial role of the therapeutic alliance in treatment effectiveness. A key focus in supervision is helping the trainee deal with the complexities of developing therapeutic alliances with multiple family members, including children, siblings, parents, and stepparents. Children are often not selfreferred, so effective rapport with a child or teenager is paramount for initial investment in therapy and a positive treatment outcome (Creed \& Kendall, 2005; Shirk \& Karver, 2003). Helping the trainee develop a strong collaborative working alliance with parents is equally important, not only for the support and maintenance of behavioral changes within the child and the family system, but also to prevent attrition or early dropout from therapy (Hawley \& Weisz, 2005). Strong evidence has emerged that receiving direct and consistent feedback on client progress can enhance psychotherapy outcomes and the therapeutic alliance (Lambert, Harmon, Slade, Whipple, \& Hawkins, 2005). The wave of the future in managed care is providing psychotherapists with patient feedback about client progress during the course of treatment, so therapists can make adjustments if treatment is not leading to improvements in patient functioning (Brown \& Jones, 2005). Supervisors can encourage the use of measures such as the Child Outcome Rating Scale and the Child Session Rating Scale (Murphy \& Duncan, 2007), so child psychologists in training can use such feedback to improve upon their therapeutic approach with each child. This will also help prepare interns or residents for inevitably being required to utilize outcome-informed or patient progress monitoring approaches in future professional practice.

Managed care training settings should also provide opportunities for refining skills in psychological assessment. Psychological testing in many HMOs can be requested by staff clinicians to clarify diagnosis and to assist in focal treatment planning. Because episodes of care may be relatively brief, turnaround of psychological test results must usually be rapid in order to be useful. Although in some cases a full test battery may be necessary, in other cases, one or two well-selected tests may be enough to answer the referral question, when integrated with data obtained from patient and collateral interviews and chart reviews (Maruish, 2002). Computer-assisted assessment often results in time saving in administration and interpretation of test instruments.

Lastly, due to managed care's emphasis on cost containment, interns and residents may face ethical problems that are more complex than those encountered in traditional mental health settings. A frequent source of frustration for trainees is the disposition of clients who continue to need care beyond the policy benefits. As noted by Spruill and Pruitt (2000), a serious ethical issue within managed care settings is the potential for patient abandonment once insurance benefits are depleted. In some managed care plans, there may be a too narrowly applied definition of "medical necessity," and psychologists in training must learn to advocate for their clients when appropriate. In discussing the issue of undertreatment and patient abandonment in managed care settings, Hoyt (2000) cautioned, "The need for cost containment needs to be constantly balanced against our prime obligations for quality care mandated by the ethical codes of all the major mental health professions" (p. 92). Fortunately, mental 
health parity with medical services is becoming increasingly mainstream in this country, thus providing more extended treatment for some children who meet the criteria for specified "parity" diagnostic conditions.

\section{Training Child Psychologists for the Future}

Managed care is a pervasive fact of life in the 21 st century that will continue to dominate health care delivery and reimbursement in the future. Whether employed in a staff- or group-model HMO, or in private practice as part of an HMO's preferred provider panel, child psychologists must be prepared to occupy a prominent place in this delivery system. Past criticism of HMOs focused on concerns about poor quality of care by restricting access to services, but due to an increasingly competitive health care marketplace, HMOs are now competing against each other based upon "quality of care," which has led to improved staffing and access to services (Reed, Levant, Stout, Murphy, \& Phelps, 2001).

Child psychologists must also be prepared for another important development in the field, namely the integration of behavioral health care into primary care settings (Cummings, 2006), a phenomenon which has taken place for years in staff-model HMOs such as Kaiser Permanente. In the future, child psychologists will be increasingly working alongside pediatricians in both institutional HMO settings and in large integrated medical/mental health group practices, where a physician can walk down the hall to consult with a behavioral health care provider who is immediately available for consultation or referral.

Well-trained child psychologists will need to occupy prominent roles in managed care's emphasis on innovative and evidenced-based approaches to individual and group therapy, the development of psychoeducational programs, and clinical outcomes research. Therefore, graduate schools, as well as internship and residency programs, must increasingly prepare child psychologists for their unique contribution to the provision of mental health services in managed care settings.

\section{Acknowledgments}

The authors are grateful to John Arden, PhD, Michael Hoyt, PhD, Miriam Wald, PhD, and Amy Schaffer, LCSW, for their reviews of this article. Conflict of Interest: None declared.

\section{References}

Annapolis Coalition on the Behavioral Healthcare Workforce (2007). An action plan for behavioral health workforce development Retrieved November 30, 2008, from http:/ www.mentalhealthcommission.gov/.

APA Presidential Task Force on Evidence-Based Practice (2006). Evidence-based practice in psychology. American Psychologist, 61, 271-285.

Austad, C. S., \& Berman, W. H. (Eds.). (1991). Psychotherapy in managed health care: The optimal use of time and resources. Washington, DC: American Psychological Association.

Barkley, R. A. (1997). Defiant children: A clinician's manual of assessment and parent training. (2nd ed.). New York: Guilford Press.

Brown, G. S., \& Jones, E. R. (2005). Implementation of a feedback system in a managed care environment: What are patients teaching us? Journal of Clinical Psychology, 61, 187-198.

Budman, S., \& Gurman, A. (1988). Theory and practice of brief therapy. New York: Guilford Press.

Chambliss, C. H. (2000). Psychotherapy and managed care: Reconciling research and reality. Boston: Allyn and Bacon.

Chwalisz, K. (2001). A common factors revolution: Let's not "cut off our own discipline's nose to 
spite its face". Journal of Counseling Psychology, 48, 262-267.

Cook, J. R., \& Tedeschi, R. G. (2007). Systems of care and the integrative clinician: A look into the future of psychotherapy. Journal of Psychotherapy Integration, 17, 139-158.

Creed, T. A., \& Kendall, P. C. (2005). Therapist alliance-building behavior within a cognitivebehavioral treatment for anxiety in youth. Journal of Consulting and Clinical Psychology, 73, 498-505.

Cummings, N. A. (1990). Brief Intermittent psychotherapy throughout the life cycle. In J. K. Zeig \& S. C. Gilligan (Eds.), Brief therapy: Myths, methods, and Metaphors (pp. 169-184). New York: Brunner/Mazel.

Cummings, N. A. (2006). Psychology, the stalwart profession, faces new challenges and opportunities. Professional Psychology: Research and Practice, 37, 598-605.

Cummings, N. A., Budman, S. H., \& Thomas, J. L. (1998). Efficient psychotherapy as a viable response to scarce resources and rationing of treatment. Professional Psychology: Research and Practice, 29, 460-469.

Daniels, J. A., Alva, L. A., \& Olivares, S. (2002). Graduate training for managed care: A national survey of psychology and social work programs. Professional Psychology: Research and Practice, 33, 587-590.

deShazer, S. (1985). Keys to solution in brief therapy. New York: Norton.

Freidberg, R. D., \& McClure, J. M. (2002). Clinical practice of cognitive therapy with children and adolescents. New York: Guilford Press.

Fry, R., Johnson, S. M., Melendez, P., \& Morgan, R. (2002). Changing destructive adolescent behavior: Parent Project Sr. (8th ed.). Ontario, CA: Parent Project.

Garfield, S. L. (1978). Research on client variables in psychotherapy. In S. L. Garfield \& A. E. Bergin (Eds.), Handbook of psychotherapy and behavior change. (2nd ed. pp. 271-298). New York: Wiley. Hansen, N. B., Lambert, M. J., \& Forman, E. M. (2002). The psychotherapy dose-response effect and its implications for treatment delivery services. Clinical Psychology: Science and Practice, 9, 329-343.
Hawley, K. M., \& Weisz, J. R. (2005). Youth versus parent working alliance in usual clinical care: Distinctive associations with retention, satisfaction, and treatment outcome. Journal of Clinical Child and Adolescent Psychology, 34, 117-128.

Hembree-Kigin, T., \& McNeil, C. (1995). Parent-child interactive therapy. New York: Plenum Press.

Hoyt, M. F. (1995). Brief therapy and managed care. San Francisco: Jossey-Bass.

Hoyt, M. F. (2000). Some stories are better than others: Doing what works in brief therapy and managed care. Philadelphia: Bruner/Mazel.

Hubble, M. A., Duncan, B. L., \& Miller, S. D. (Eds.). (1999). The heart and soul of change: What works in therapy. Washington, DC: American Psychological Association.

Jung, R. M., Pomerantz, A. M., Tuholski, S. W., \& Sullivan, B. F. (2001). The impact of specific psychotherapist beliefs regarding managed care on prospective psychotherapy clients.

Journal of Contemporary Psychotherapy, 31, 151-160.

Kazdin, A. E. (1997). Parent management training: Evidence, outcomes, and issues. Journal of the American Academy of Child and Adolescent Psychiatry, 36, 1349-1356.

Kazdin, A. E., \& Weisz, J. R. (Eds.). (2003). Evidencebased psychotherapies for children and adolescents. New York: Guilford Press.

Kendall, P. C., \& Beidas, R. S. (2007). Smoothing the trial for dissemination of evidence-based practices for youth: Flexibility within fidelity. Professional Psychology: Research and Practice, 38, 13-20.

Kreilkamp, T. (1989). Time-limited intermittent therapy with children and families. New York: Bruner Mazel.

Lambert, M. J., \& Ogles, B. M. (2004). The efficacy and effectiveness of psychotherapy. In M. J. Lambert (Ed.), Bergin and Garfield's handbook of psychotherapy and behavior change. (5th ed. ). New York: John Wiley \& Sons.

Lambert, M. J., Harmon, C., Slade, K., Whipple, J. L., \& Hawkins, E. J. (2005). Providing feedback to psychotherapists on their patients' progress: Clinical results and practice suggestions. Journal of Clinical Psychology, 61, 165-174. 
March, J. S., \& Mulle, K. (1998). OCD in children and adolescents: A cognitive-behavioral treatment manual. New York: Guilford Press.

Maruish, M. E. (2002). Psychological testing in the age of managed behavioral health care. Mahwah, NJ: Lawrence Erlbaum Associates.

Miller, A. L., Rathus, J. H., \& Linehan, M. M. (2007). Dialectical behavior therapy with suicidal adolescents. New York: Guilford Press.

Miller, S. A., Wampold, B. E., \& Varhely, K. (2008). Direct comparisons of treatment modalities for youth disorders: A meta-analysis. Psychotherapy Research, 18, 5-14.

Murphy, J. J., \& Duncan, B. L. (2007). Brief intervention for school problems: Outcome-informed strategies. New York: Guildford Press.

Ollendick, T. H., \& King, N. J. (1998). Empirically supported treatments for children with phobic and anxiety disorders. Journal of Clinical Child Psychology, 27, 156-167.

Orlinsky, D. E., \& Howard, K. I. (1986). Process and outcome in psychotherapy. In S. L. Garfield \& A. E. Bergin (Eds.), Handbook of psychotherapy and behavior change. (3rd ed. pp. 311-381). New York: Wiley.

Peake, T. H., Borduin, C. M., \& Archer, R. P. (2000). Brief psychotherapies: Changing frames of mind. New York: Jason Aronson.

President's New Freedom Commission on Mental Health (2003). Final report to the President Retrieved November 30, 2008, from http:// www.mentalhealthcommission.gov/.

Reed, G. M., Levant, R. F., Stout, C. E., Murphy, M. J., \& Phelps, R. (2001). Psychology in the current mental health marketplace. Professional Psychology: Research and Practice, 32, 65-70.

Robin, A. L. (2003). Behavioral family systems therapy for adolescents with anorexia nervosa. In A. E. Kazdin \& J. R. Weisz (Eds.), Evidencebased psychotherapies for children and adolescents (pp. 358-373). New York: Guilford Press.
Shirk, S. R., \& Karver, M. (2003). Prediction of outcome from relationship variables in child and adolescent therapy: A meta-analytic review.

Journal of Consulting and Clinical Psychology, 71, 452-464.

Spielmans, G. I., Pasek, L. F., \& McFall, J. P. (2007). What are the active ingredients in cognitive and behavioral psychotherapy for anxious and depressed children? A meta-analytic review. Clinical Psychology Review, 27, 642-654.

Spruill, J., \& Pruitt, S. D. (2000). Preparing psychologists for managed care settings: Enhancing internship training programs. Professional Psychology: Research and Practice, 31, 305-309.

Szapocznik, J., \& Williams, R. A. (2000). Brief strategic family therapy: Twenty-five years of interplay among theory, research and practice in adolescent behavior problems and drug abuse. Child and Family Psychology Review, 3, 117-134.

Wachtel, E. F. (1994). Treating troubled children and their families. New York: Guilford Press.

Wampold, B. E. (2001). The great psychotherapy debate: Models, methods, and findings. Mahwah, NJ: Erlbaum.

Weisz, J. R., Jensen-Doss, A., \& Hawley, K. M. (2006). Evidence-based youth psychotherapies versus usual clinical care. American Psychologist, 61, 671-689.

Westen, D., \& Bradley, R. (2005). Empirically supported complexity: Rethinking evidencebased practice in psychotherapy. Current Directions in Psychological Science, 14, 266-271.

Westen, D., Novotny, C. M., \& ThompsonBrenner, H. (2004). The empirical status of empirically supported psychotherapies: Assumptions, findings, and reporting in controlled clinical trials. Psychological Bulletin, $130,631-663$. 